\title{
Student perception of electronic resources use in Rajshahi University Library: A case study
}

\author{
Kazi Mostak Gausul Hoq ${ }^{1}$ and Md. Armanul Haque ${ }^{2^{\star}}$ \\ ${ }^{1}$ Information Science and Library Management, University of Dhaka, Bangladesh. \\ ${ }^{2}$ Information Science and Library Management, University of Rajshahi, Bangladesh.
}

Received 27 February, 2018; Accepted 14 June, 2018

\begin{abstract}
The growing use of electronic resources in and outside the libraries has become a major issue of discussion all over the world. Information seekers, particularly students and teachers are becoming key proponents of e-resource use. Against this backdrop, this paper explores the pattern of e-resource use by undergraduate and post-graduate students of Rajshahi University - one of the oldest and largest universities in Bangladesh. Based on a questionnaire based survey, the paper comes up with some key findings on the e-resource use pattern by the students as well as some recommendations for increasing the use of e-resources in the coming days.
\end{abstract}

Key words: Electronic resources, libraries, Rajshahi University, Bangladesh, e-book, e-journal.

\section{INTRODUCTION}

Electronic resources (ER), more commonly known as eresources, have gradually taken a central position in library collections all over the world. With the growing popularity of digital libraries, e-resources now form the major part of many library collections. With the emergence of new techniques and technologies, electronic information sources are becoming more and more important for the academic community and an awareness of these resources is of paramount importance to library development in the 21st century (Velmurugan, 2013; Akpojotor, 2016). The use of eresources has created new opportunities as well as new challenges for library professionals as they are trying to come up with new techniques and approaches for managing their electronic collections and providing dynamic library services using a whole range of new technologies. The users, on their part, also are trying to cope with the changing situations by making diversified use of electronic resources although many users are still skeptical about the real potentials of electronic resources. Besides, the adoption of e-resources and digital technologies has not been similar in all parts of the world, with developed countries making significant advances in this regard while many developing countries lag behind. Against this backdrop, exploring the nature and dimensions of e-resource use has become quite important, as it will help understand the significance of eresources in library collections at present and in the future.

\section{Electronic resources: Definition and nature}

Simply said, e-resources are resources that are produced, preserved, managed, used and shared by electronic means.

${ }^{*}$ Corresponding author. E-mail: armanul_haque@ru.ac.bd. 
They require the use of additional tools including computers, e-book reader, smart phone, etc. IGI Global defines e-resources as 'all the information products that a library provides through a computer network. This includes electronic books and journals, bibliographic databases, and library website pages (IGI Global). Library of Congress defines e-resources as 'any work encoded and made available for access through the use of a computer. It includes data available by:

(1) Remote access and

(2) Direct access (Library of Congress).

From the viewpoint of International Federation of Library Associations and Institutions (IFLA), electronic resources refer to 'those materials that require computer access, whether through a personal computer, mainframe, or handheld mobile device. They may either be accessed remotely via the internet or locally (IFLA, 2012).' Today's library and information centres deal with a wide range of e-resources which include electronic journals, electronic books, full-text databases, indexing and abstracting services, reference databases, statistical databases, audio and visual materials and so on. With the proliferation of e-resources and their increasing use by a wide number of learners, libraries have been trying to make these resources available to their users. This has created some unique challenges for the libraries as well as an opportunity to serve their clients more effectively.

\section{LITERATURE REVIEW}

There have been numerous studies on the use and impact of e-resources by various groups of users, viz. students, teachers, researchers, general information seekers, etc. These studies have focused on various aspects of e-resource use (including constraints and challenges faced by the users) and attempted to put forward recommendations for the improvement of $\mathrm{e}$ resource use. Since it will be next to impossible to present a comprehensive picture of these studies, we will confine our literature review to a few representative studies from Bangladesh.

Islam and Habiba (2015) conducted a research on the e-resources use in a leading private university in Bangladesh and their research findings showed that, although the students and faculty members were generally satisfied with the quality of internet and eresources, they also faced constraints like limited number of titles, difficulty in finding information, limited access to computers, slow download speed, etc. A study conducted by Mostafa (2013) on the use and impact of e-resources at some private university libraries in Bangladesh revealed that an increasing number of users are becoming dependent on e-resources for study and research purposes. However, the existing infrastructural facilities of the libraries were found to be adequate for supporting optimum use of e-resources.

Islam and Mostafa (2013) suggested conducting an exhaustive survey to analyze the existing e-resources of different libraries of Bangladesh as well the infrastructural facilities and users needs. They also recommended for the formulation of an action plan based on the findings of the proposed study. Habiba and Chowdhury (2012) while analyzing the use of e-resource by the users of Dhaka University Library, one of the largest libraries in Bangladesh, found that, the frequency and volume of eresource use are increasing gradually with the majority of the users consulting e-resources for learning and current information. Tabassum et al. (2015) identified lack of awareness, adequate manpower, infrastructural facilities, etc. as major obstacles for effective use of digital library resources and advocated for the development of physical and infrastructure, human resource development, user education programmes, etc. for improving the condition. By exploring the pattern of e-resource use by the students of Rajshahi University, this paper aims at:

(1) Gaining an in-depth understanding of the acceptability and use pattern of e-resources by the students of one of the largest universities in Bangladesh.

(2) Exploring the strengths and weaknesses of $e$ resource collection of Rajshahi University.

(3) Putting forward recommendations for improving the eresource collections and services by Rajshahi University.

\section{METHODOLOGY}

The University of Rajshahi, founded in July 1953, is one of the largest Universities in the country with the highest seat of learning in the northern region of Bangladesh. It has 33.200 students studying in 56 departments which are organized into 10 Faculties (Rajshahi University Diary, 2016). The present study is based on a questionnaire based survey of the students of the University of Rajshahi. It also reviewed a number of pertinent literatures. The study was carried out over a period of one month - February 2017. A structured questionnaire was served among 180 students of Rajshahi University. Of them, 138 students returned the duly filledin questionnaire. While selecting the respondents, steps were taken to make sure that an equal representation of students from the Faculties of Arts, Science and Social Sciences is ensured. Respondents were chosen randomly from each faculty's department. 60 students were from each faculty. In some cases, it was necessary to clarify a few questions to the students where they were unsure of the question asked and its implications. The study findings were analyzed with the help of statistical package for social sciences (SPSS).

\section{RESULTS AND DISCUSSION}

Table 1 show the degree of participation by the respondents. Out of the 138 questionnaires served, only 6 were not returned. This indicated that the level of response was quite high. Table 2 show the frequency of library use by the respondents. It shows that the highest number of respondents visit the library 4 to 5 days a 
Int. J. Lib. Inf. Sci.

Table 1. Degree of participation by the respondents.

\begin{tabular}{lcc}
\hline Category & Number of respondents & Percentage \\
\hline Yes & 132 & 96.65 \\
No & 6 & 4.36 \\
\hline
\end{tabular}

Table 2. Frequency of library use.

\begin{tabular}{lcc}
\hline Category & Number of respondents & Percentage \\
\hline Everyday & 24 & 17.39 \\
4-5 days a week & 63 & 46.65 \\
1-3 days a week & 42 & 30.43 \\
Others & 9 & 6.52 \\
\hline
\end{tabular}

Table 3. Perception about usefulness of ERs for students.

\begin{tabular}{lcc}
\hline Category & Number of respondents & Percentage \\
\hline Very much useful & 69 & 50 \\
Useful & 54 & 39.13 \\
Only nominally useful & 9 & 6.52 \\
Not as useful as it is thought & 3 & 2.17 \\
Not at all useful & 00 & \\
\hline
\end{tabular}

week. They are followed by $30.43 \%$ of users, who visit the library 1 to 3 days a week. A sizable number of students $(17.39 \%)$ visit the library everyday, which is quite encouraging.

Table 3 indicates that, the students' perception about the usefulness of electronic resources is very positive. Exactly half of the respondents believe that ERs are useful tool for study purposes. Another 39.13\% respondents believe that ERs are useful. Only a very small faction $(2.17 \%)$ of students feel that ERs are not as useful as is generally thought. Another interesting finding of the survey is that, not a single respondent feel that ERs are not at all useful. Table 4 represents the use of ERs by category. The highest percentage of users $(67.30 \%)$ use electronic books while websites are used by $45.65 \%$ students. The table indicates that e-journals and e-newspapers also are in good demand as they are used by a sizable number of respondents $-32.61 \%$ and $30.43 \%$ respectively. Databases are used by the least number of respondents (13.04\%).

Table 5 presents the perceived benefits of the ERs as indicated by the respondents. Most of them (58.68\%) think that ERs' greatest merit is quick search and retrieval facility. Ease of use of the ERs is indicated as its greatest merit by $17.39 \%$ respondents. Other merits being preferred by the respondents include printing and reproduction (10.87\%), remote access $(10.87 \%)$ and opportunity for sharing $(8.70 \%)$. Although the reliability of websites as information source is questioned by many, Table 6 shows that, an excessively high percentage of the respondents $(93.47 \%)$ consider websites as reliable source of information. Only $6.52 \%$ respondents have doubts about the reliability of websites as source of information (Table 6).

The respondents have divided opinions about the favourable characteristics of websites. Majority of the respondents $(65.12 \%)$ maintain that, the favourability of the websites rests primarily on the fact that, they provide latest information. $20.93 \%$ respondents think, the fact that websites could be accessed from any place with an internet connection is the main reason of their favourability. The ease of use of the websites has been cited by $20.93 \%$ respondents as their most favourable feature (Table 7). As it has been previously indicated, only 9 of the 138 respondents view websites unfavourably as a source of information. Table 8 shows that the reasons of unfavourability of websites vary from false information provision (44.44\%), difficulty of use $(33.33 \%)$ and long time for loading.

Table 9 presents the perception of the respondents regarding the urgency of enriching the collection of electronic resources of Rajshahi University. It shows that, an overwhelming majority of respondents feel that the authority of Rajshahi University Library needs to take immediate steps for enriching its ER collection. Only a low percentage of students $(6.52 \%)$ feel the opposite, 
Table 4. Use of ERs by category.

\begin{tabular}{lcc}
\hline Category & Number of respondents & Percentage \\
\hline e-books & 93 & 67.39 \\
e-journals & 45 & 32.61 \\
e-newspaper & 42 & 30.43 \\
Websites & 63 & 45.65 \\
Databases & 18 & 13.04 \\
\hline
\end{tabular}

Table 5. Perception about benefits of using ERs.

\begin{tabular}{lcc}
\hline Category & Number of respondents & Percentage \\
\hline Quick search and retrieval & 81 & 58.68 \\
Ease of use & 24 & 17.39 \\
Opportunities for sharing & 12 & 8.70 \\
Printing and reproduction & 15 & 10.87 \\
Remote access (could be read from remote location) & 15 & 10.87 \\
Others & 3 & 2.17 \\
\hline
\end{tabular}

Table 6. Perception about reliability of websites as source of information.

\begin{tabular}{lcc}
\hline Category & Number of respondents & Percentage \\
\hline Yes & 129 & 93.47 \\
No & 9 & 6.52 \\
\hline
\end{tabular}

Table 7. Favourable characteristics of websites.

\begin{tabular}{lcc}
\hline Category & Number of respondents & Percentage \\
\hline Websites provide latest information & 84 & 65.12 \\
Websites are easy to use & 18 & 13.95 \\
Websites provides accurate information & 12 & 9.30 \\
Websites could be accessed from any place with an internet connection & 27 & 20.93 \\
\hline
\end{tabular}

Table 8. Unfavourable characteristics of websites.

\begin{tabular}{lcc}
\hline Category & Number of respondents & Percentage \\
\hline Websites may provide false information & 4 & 44.44 \\
Websites are not easy to use for all & 3 & 33.33 \\
Websites may take a long time to load & 2 & 22.22 \\
\hline
\end{tabular}

Table 9. Perception about the urgency of enriching the digital collection of $\mathrm{RU}$ Library.

\begin{tabular}{lcc}
\hline Category & Number of respondents & Percentage \\
\hline Yes & 129 & 93.48 \\
No & 9 & 6.52 \\
\hline
\end{tabular}


Table 10. Reasons for enriching the digital collection of RU Library.

\begin{tabular}{lcc}
\hline Category & Number of respondents & Percentage \\
\hline It will help students excel in their studies & 42 & 32.55 \\
It will enhance the learning capacity of the students & 51 & 39.53 \\
It will enhance the career prospect for the students & 21 & 16.59 \\
It will help teacher impart better educations & 6 & 4.65 \\
It will enhance the ICT skills of the students & 17 & 13.18 \\
\hline
\end{tabular}

Table 11. Perception about the disadvantages of ERs.

\begin{tabular}{lcc}
\hline Category & Number of respondents & Percentage \\
\hline It is not cost-effective & 15 & 10.87 \\
It does not give the full satisfaction of reading & 66 & 47.83 \\
It is not easy to use & 15 & 10.87 \\
It is not suitable for all students & 24 & 17.39 \\
Its value is over-estimated, there is no real benefit in using ER? & 3 & 2.17 \\
\hline
\end{tabular}

Table 12. Opinions about ways for promoting the use of ERs.

\begin{tabular}{lcc}
\hline Category & Number of respondents & Percentage \\
\hline Allocate more budgets for procuring ER & 120 & 86.96 \\
Development skills and capacity of students and staffs & 90 & 65.22 \\
Raise awareness on the importance of ER & 63 & 45.65 \\
Undertake educational campaign & 27 & 19.57 \\
Digitize the existing print collection & 15 & 10.87 \\
\hline
\end{tabular}

that is, the urgency for enriching the ER collection of the library is not very acute.

Table 10 indicates the respondents' opinion about why the ER collection of RU Library should be enriched immediately vary widely. However, majority of the respondents (39.53\%) think that it should be done to help students enhance their learning capabilities. Moreover, the second highest numbers of (32.55\%) students feel that it will help students excel in their studies, while $16.59 \%$ believe that this will enhance the career prospects for RU students. The number of students who feel that enriching the ER collection of the library will help students acquire and upgrade the ICT skills constitute $13.18 \%$ of the respondents.

Table 11 presents the perceived disadvantages of the electronic resources as identified by the respondents. It shows that, the largest number of respondents (47.82\%) feel that, the most notable disadvantage of ERs is that, it does not give the reader the full satisfaction of reading, which they find in printed materials. The second most notable disadvantage of the ERs (as perceived by the respondents) is that, it is not suitable for all kinds of students (17.39\%). The cost-effectiveness and difficulty of use of the ERs have been cited as its most notable disadvantage by an equal $10.87 \%$ of the respondents.

Table 12 presents the opinions of the respondents about how the use of electronic resources could be promoted among the students and other users of Rajshahi University Library. This shows that, a vast majority of the respondents feel that, the use of ERs could be promoted by allocating more budget for strengthening the ER collection. The opinion that has been expressed by the second highest number of respondents $(65.22 \%)$ is skills and capacity development of library staff and students, which is followed by awareness raising on the importance of ERs. A sizable number of respondents have also advocated for undertaking educational campaign and digitizing the existing print collections, which have been suggested by 19.57 and $10.87 \%$ respondents respectively.

Table 13 presents the respondents' forecast about the trend of ER use by RU students in near future. It indicates that, more than half of the respondents $(58.70 \%)$ think that the use of ERs by RU students will increase significantly in the near future, while $17.39 \%$ believe that it will increase marginally. Only $4.34 \%$ 
Table 13. Perception about the proliferation of ER use by $R U$ students in near future.

\begin{tabular}{lcc}
\hline Category & Number of respondents & Percentage \\
\hline It will increase substantially & 81 & 58.70 \\
It will increase marginally & 24 & 17.39 \\
It will remain the same as now & 6 & 4.34 \\
It will decrease marginally & 3 & 2.17 \\
It will decrease substantially & 1 & 0.72 \\
I have no idea & 1 & 0.72 \\
\hline
\end{tabular}

students think that it will remain at the present level. The number of students who think that it will actually decrease rather than increase is extremely low $(0.72 \%)$, and similar percentage of students informed that they have no idea whether it will increase or decrease or remain the same.

\section{DISCUSSIONS}

The study has come up with some key findings, which provide interesting insights into the use of electronic resources by the students of the University of Rajshahi. It also helps understand the perceptions of the library users regarding the current and future trends of the use of electronic resources. The major findings of the study can be summarized as follows:

(1) The acceptability of electronic resources as a study tool is quite high among the students who took part in the survey. Approximately $90 \%$ of the respondents believe that ERs are either extremely or moderately useful for their study. Therefore, the university authority should take steps to promote the use of electronic resources by the students by investing more in building ER collection in the library.

(2) Although the issue of e-book use by students has drawn both positive and negative reactions from various quarters (Picton, 2014), the study finds that, students of Rajshahi University generally regard e-book favourably as study tools. Another interesting finding is that, they prefer websites to electronic journals as study tool. This is interesting because e-journals are generally thought to be more reliable source of information than websites. The use of databases by students is quite low, which is understandable, because usually faculty members and researchers are the main users of databases.

(3) One of the most important features of ERs as compared to print materials is quick and easy search and retrieval, which has been supported by the majority of the respondents. Therefore, the search and retrieval functions of the ERs should be made more effective so that their use could be further enhanced. The survey indicates that, the remote access facilities of the ERs should also be enhanced so that more students could use it for their study purposes.
(4) Although the reliability of websites as study tools has been questioned in many studies (Brandstorm, 2011; Sahin et al., 2010), websites are still preferred by many students for study purposes and this fact has been supported by the present study as well. However, it is advisable for the students to evaluate the reliability of the websites by judging their accuracy, currency, objectivity, scope, authority, authenticity, etc.

(5) The present study ascertains that the utility and potentials of electronic resources for helping students enhance their learning capacities is greatly appreciated by the students. This is why they rely on ERs for excelling in their studies and many students regard ERs as a facilitator of their career prospects. By focusing on this fact, the RU Library authority should take steps for enriching and diversifying the ER collection of the RU Library so that students can benefit more from these resources.

\section{Conclusion}

The use of electronic resources is on the rise all over the world. Against this backdrop, Bangladeshi university libraries also are enriching their ER collections in various ways. Rajshahi University has been in the forefront of this initiative through steadily building a stable and diversified ER collection and making these collections available to students, teachers and other users. The present study confirms that the students of Rajshahi University are fully aware of the significance of ERs and support this ongoing initiative of digitization and electronic collection building. Therefore, the University authority should step up their effort to enrich the electronic resource collection of $R U$ Library under a well thought-out plan and long term policies. This will not only help the students and other library users get up-to-date knowledge and information, but will also contribute in the educational excellence of Rajshahi University.

\section{RECOMMENDATIONS}

(1) RU authority should allocate more budgets for strengthening the ER collection of the RU Library. 
(2) Besides, steps should be taken to upgrade the skills and competence of library staff so that they can offer better services to the users.

(3) Moreover, steps like awareness raising on the importance of ERs among the users.

(4) Large scale digitization of print materials, undertaking educational initiatives regarding ERs could also contribute in enhancing the use and acceptability of ERs.

(5) A regular basis training, workshop on the usages of eresources should be conducted faculty wise among the students.

(6) A high speed of internet connection should be ensured.

(7) The campus should be taken under Wi-fi in order to ensure the widespread use of the electronic library.

(8) Uninterrupted power supply should be ensured campus wide.

(9) Teachers should encourage students to use the electronic library materials.

\section{CONFLICT OF INTERESTS}

The authors have not declared any conflict of interests.

\section{REFERENCES}

Akpojotor LO (2016). Awareness and usage of electronic information resources among postgraduate students of library and information science in southern Nigeria. Library Philosophy and Practice (ejournal). Paper 1408. Retrieved from http://digitalcommons.unl.edu/libphilprac/1408 on 2 March 2017.

Brandstorm C (2011). Using the Internet in education - strengths and weaknesses: a qualitative study of teachers' opinions on the use of the Internet in planning and instruction. Retrieved from www.divaportal.org/smash/get/diva2:438827/FULLTEXT01.pdf on 3 March 2017.

Habiba U, Chowdhury S (2012). Use of electronic resources and its impact: a study of Dhaka University library users. The Eastern Librarian 23(1):74-90.

Islam M, Habiba U (2015). Using Pattern of Internet and E-resources by the Students and Faculty Members of a Private University in Bangladesh. American Journal of Educational Research 3(5):541-546

Islam S, Mostafa SM (2013). A review of digital resources among different types of libraries in Bangladesh. International Journal of Humanities and Social Sciences 2(1):109-120.
Mostafa SM (2013). Use and impact of e-resources at some selected private universities in Bangladesh. Research Journal of Library Science 1(1):10-13.

Picton I (2014). The impact of ebooks on the reading motivation and reading skills of children and young people: a rapid literature review. Retrieved from http://www.literacytrust.org.uk/assets/0002/3898/Ebooks_lit_review_2 014.pdf on 18 February 2017.

Sahin YG, Balta S, Ercan Y (2010). The use of Internet resources by University students during their course projects elicitation: a case study. The Turkish Online Journal of Educational Technology 9(2):234-44.

Tabassum M, Roknuzzaman M, Islam MM (2015). Usage of a digital library system at a private university library in Bangladesh. Annals of Library and Information Studies 62(2):94-103.

Velmurugan C (2013). Use and user perception of electronic information resources: A case study of Siva Institute of Frontier Technology, India. Chinese Librarianship: International Electronic Journal 36. Retrieved from http://www.iclc.us/cliej/cl36chandran.pdf on 11 February 2017. 